\title{
Modeling Parkinson's Disease in Primates: The MPTP Model
}

\author{
Gregory Porras ${ }^{1,2}$, Qin Li ${ }^{3}$, and Erwan Bezard ${ }^{1,2,3}$ \\ ${ }^{1}$ Univ. de Bordeaux, Institut des Maladies Neurodégénératives, UMR 5293 Bordeaux, France \\ ${ }^{2}$ CNRS, Institut des Maladies Neurodégénératives, UMR 5293 Bordeaux, France \\ ${ }^{3}$ Institute of Lab Animal Sciences, China Academy of Medical Sciences, Beijing 100021, China \\ Correspondence: erwan.bezard@u-bordeaux2.fr
}

The 1-methyl-4-phenyl-1,2,3,6-tetrahydropyridine (MPTP) primate models of Parkinson's disease (PD) reproduce most, although not all, of the clinical and pathological hallmarks of PD. The present contribution presents the possibilities offered by the MPTP monkey models of $\mathrm{PD}$ to readers with minimal knowledge of PD, emphasizing the diversity of species, route and regimen of administration, symptoms and pathological features. Readers would eventually find out that there is not a single MPTP monkey model of PD but instead MPTP monkey models of PD, each addressing a specific experimental need.

$P_{e}^{2}$ arkinson's disease (PD) is a neurodegenerative disorder whose cardinal manifestations are due primarily to a profound deficit in brain dopamine. Several therapeutic strategies have been discovered to treat the symptoms of this neurological disorder, but, as of yet, none halts or retards the neurodegenerative process. In an attempt to shed light into the neurobiology of PD, a number of experimental models have been developed, especially during the last 25 years. In 1982, a cluster of young drug addicts came down with a clinical picture almost indistinguishable from PD after the self-administration of a synthetic heroin analogue contaminated by 1-methyl-4-phenyl-1,2,3,6-tetrahydropyridine (MPTP). The resemblance to PD was so striking that researchers quickly tested this compound in various animal species and showed that MPTP administration was able to reproduce most, but not all, of the clinical and pathological hallmarks of PD in monkey (Chiueh et al. 1984; Langston et al. 1984; Crossman et al. 1985; Doudet et al. 1985) and, at least the degeneration of dopaminergic neurons in mice (Heikkila et al. 1984), but not in rats which were found to be resistant to this toxin (Chiueh et al. 1984).

The aim of the present contribution is not to review recent data, but rather to present the possibilities offered by the MPTP monkey model of PD to readers with minimal knowledge of $\mathrm{PD}$ for them to be ready to start working on $\mathrm{PD}$.

\section{PD PHENOMENOLOGY}

The first issue is to recognize what we are aiming for in modeling. PD is characterized, in part, by a progressive loss of dopamine neurons in

Editor: Serge Przedborski

Additional Perspectives on Parkinson's Disease available at www.perspectivesinmedicine.org

Copyright (C) 2012 Cold Spring Harbor Laboratory Press; all rights reserved; doi: 10.1101/cshperspect.a009308

Cite this article as Cold Spring Harb Perspect Med 2012;2:a009308 
G. Porras et al.

the substantia nigra pars compacta $(\mathrm{SNc})$. The progressive dorso-ventral dopamine depletion of the striatum causes the classical motor signs of bradykinesia, rigidity, and resting tremor. These symptoms are improved by current dopamine-replacement strategies including levodopa (L-dopa, the precursor of dopamine). After several years of disease progression, treatment is complicated by the onset of motor fluctuations and dyskinesia, leading to alternating periods of reduced mobility and abnormal involuntary movements. Some patients receiving dopaminergic drugs also develop abnormal behaviors, including impulse control disorders or dopamine dysregulation syndrome.

Besides dopamine, the neurodegenerative process involves other neurotransmitters such as noradrenergic, serotoninergic, and cholinergic systems. Nonmotor signs such as depression, dementia, sleep abnormalities and autonomic failure-which manifests as symptomatic orthostatic hypotension, urinary incontinence and constipation - are the likely consequence of degeneration of both dopaminergic and nondopaminergic systems.

\section{MODELS RATHER THAN MODEL OF PD}

The literature often refers to "the" MPTP monkey model of PD but we will find out that we should instead speak about MPTP monkey models of PD. First of all, a few species have been used over the years. The old-world primates species currently used in PD research feature the Chlorocebus sabaeus (African green monkey also called the vervet monkey), the Macaca mulatta (rhesus) and the Macaca fascicularis (cynomolgus) while the representatives of the new world monkeys are the Saimiri sciureus (squirrel monkey) and the Callithrix jacchus (marmoset). They have been used to varying degrees and for specific uses that will be covered in this review. To further add to the complexity, a number of intoxication regimen or administration methods have been used over the years. Unilateral models have been first developed after intracarotidian administration of MPTP to macaques (Benazzouz et al. 1993; Kordower et al. 1995). This method was soon followed by various regimen of systemic administration, through i.m., s.c. or i.v. routes, over few days, weeks, or months (Langston et al. 1984; Rose et al. 1993; Bezard et al. 1997, 2001b,c; Morissette et al. 1999; Di Monte et al. 2000; Iravani et al. 2003; Jan et al. 2003; Meissner et al. 2003). Infusion of MPTP with osmotic minipump is also applied over few months followed by final titration with systemic i.m. shots (Belanger et al. 2003; Hadj Tahar et al. 2004; Ouattara et al. 2009).

\section{MPTP-INDUCED ANATOMO-PATHOLOGY}

Primary effect of MPTP exposure will be to deplete DA levels through the induction of nigrostriatal degeneration. Doubts were raised in the early days (and still persist) about whether the patterns of nigrostriatal fiber loss were similar after MPTP exposure and in PD. Low dose MPTP exposure actually produces a pattern of nigrostriatal degeneration characteristic of that seen in PD, in which there is a greater depletion of dopaminergic markers in the putamen that in the caudate nucleus (Moratalla et al. 1992; Jan et al. 2003; Iravani et al. 2005), especially at posterior rostro-caudal level. Moreover, within the regions of diminished dopaminergic markers, there is substantial preservation in striosomes relative to the surrounding matrix (Moratalla et al. 1992). Higher doses or stronger regimens of intoxication, although generating more comprehensive behavioral phenotypes, abolish these differences with more homogenous pattern of denervation in putamen and caudate while the ventral striatum remains less affected (Bezard et al. 2001c; Meissner et al. 2003; Guigoni et al. 2005; Fernagut et al. 2010).

Interestingly, the MPTP neurotoxin is often presented as being "selective of DA neurons." Hence, few studies have investigated either the DA loss outside the nigrostriatal system or the loss of other neurotransmitters. Pifl and collaborators executed an insightful study (Pifl et al. 1991) in which they measured the tissue concentration of the monoamines DA, noradrenaline and serotonin in 45 brain regions in macaques monkeys chronically intoxicated 
with systemic MPTP over few weeks. None of the three major brain monoamine neuron systems was completely resistant to the neurotoxin. In addition, each brain monoamine had a characteristic regional pattern of MPTP-induced changes. The most significant alterations were found within the nigrostriatal dopamine system, i.e., profound DA loss in caudate nucleus, putamen and SNc. However, many extrastriatal regions of the subcortex and brainstem also suffered significant loss of dopamine, with the noradrenaline loss in the regionally subdivided brainstem being less widespread, and the serotonin levels least affected. Thus, in subcortex/brainstem the ranking order of sensitivity to MPTP was: DA > noradrenaline serotonin. In the cerebral (neo- and limbic) cortex, all three monoamine neuron systems suffered widespread statistically significant losses. This study showed that in the macaque monkey MPTP mimicked, in addition to the profound striatal dopamine loss, some of the extrastriatal DA, noradrenaline and serotonin changes often seen in the brain of patients with idiopathic PD (Pifl et al. 1991). Finally, MPTP toxicity outside the brain should also be considered. Impact of MPTP on DA system in spinal cord (Barraud et al. 2010) and even the enteric nervous system has been analyzed in that respect (Chaumette et al. 2009).

A classic opposition to the model is the lack of Lewy bodies (LB), the pathological landmark of PD, in the MPTP monkey models. Although no LB have so far been indeed observed in these models, a few reports have investigated the expression, regulation and/or pattern of a LB major constituent, $\alpha$-synuclein, after MPTP exposure. Di Monte and coworkers were instrumental for this topic delivering pivotal findings (Purisai et al. 2005). They studied the relationship between toxic injury and $\alpha$-synuclein expression in the SNc of squirrel monkeys treated with a single injection of MPTP and sacrificed 1 week or 1 month later. At 1 week, when stereological cell counting revealed only a small decrease $(10 \%)$ in the number of dopaminergic neurons, $\alpha$-synuclein mRNA and protein were markedly enhanced. Increased $\alpha$-synuclein immunoreactivity was evident at the level of neuronal fibers whereas nigral cell bodies were devoid of detectable protein. At 1 month postMPTP, neuronal loss rose to $40 \%$. Both $\alpha$-synuclein mRNA and protein remained elevated but, noticeably, a robust $\alpha$-synuclein immunoreactivity characterized a significant number of cell bodies. Even more important was the finding that the vast majority of $\alpha$-synuclein-immunoreactive neurons contained neuromelanin granules (Purisai et al. 2005), the hallmark of dopaminergic neurons in primates and man, and approximately $80 \%$ of the dopaminergic cell bodies that survived MPTP toxicity stained positive for $\alpha$-synuclein.

Following these seminal data, we investigated the issue throughout the brain of MPTPintoxicated macaques looking at $\alpha$-synuclein, tau, gliosis (Vital et al. 2010). Our data revealed a widespread immunoreactivity for both $\alpha$ synuclein and tau in several brain regions of the MPTP-lesioned macaques. These included the substantia nigra, pons, medulla oblongata and cerebellum (dentate nucleus). GFAP staining was marked in the substantia nigra and pallidum. Interestingly, although the tauopathy was not corrected by the levodopa treatment, the immunostaining for $\alpha$-synuclein was clearly reduced in the pallidum, pons, medulla oblongata, and cerebellum but not in the substantia nigra (Vital et al. 2010). This study extends the validity of the MPTP-lesioned macaque model of PD to pathological findings. In addition, it suggests that while $\alpha$-synuclein increased expression is levodopa-insensitive in the substantia nigra, it is sensitive to dopamine replacement therapy in other brain regions. These data therefore offer a window for studying dopamine/ synuclein interactions and their consequences on widespread neurodegeneration.

\section{MPTP-INDUCED PHENOCOPY OF PD}

\section{Motor Triad}

MPTP-induced parkinsonism in monkeys produces an amazing phenocopy of PD. In the early days of MPTP, most researchers focused on the bradykinesia/akinesia and rigidity analogy to PD with clear-cut demonstration of the 
G. Porras et al.

similarities. Quoting the first mechanographic study (Doudet et al. 1985, 1986, 1990), the researchers describe that "after MPTP treatment, alterations in movement parameters and EMG activity were observed. Mean reaction time and movement duration increased by $20 \%-$ $25 \%$ and $25 \%-30 \%$, respectively. The movements were slower and were associated with a generalized depression in the shape and the amplitude of EMG activity in the agonist muscle." UPDRS-like clinical rating also assess such behavioral features (Imbert et al. 2000). Mechanographic studies have been overwhelmed by such clinical ratings despite their soundness (Benazzouz et al. 1992, 1993) mostly for the sake of time and expertise they require.

The third main symptom of PD, tremor, is maybe the only symptom seldom reproduced in monkeys. It seems however that it is more a species issue. Indeed, while macaque monkeys seldom display the typical PD rest tremor (but clearly show action and postural tremor) (Bezard et al. 1998), the MPTP-intoxicated Chlorocebus sabaeus (African green monkey also called the vervet monkey) does display a validated rest tremor (Raz et al. 2000; Guehl et al. 2003).

\section{Cognitive Impairment}

After the first years, researchers have turned their interest toward other motor and nonmotor symptoms. Among those, the cognitive disturbances reported in $\mathrm{PD}$ patients have retained their interest. To specifically address those cognitive impairments, Schneider and colleagues developed an intoxication paradigm in the macaque monkey leading to cognitive impairment before the motor symptom take place (Schneider 1990; Schneider and Kovelowski 1990; Roeltgen and Schneider 1991, 1994; Schneider et al. 1992; Schneider and Roeltgen 1993). MPTP is administered at low doses, several times per week for several months. MPTP administration continues until cognitive deficits appear in the absence of parkinsonian motor impairment. Animals are considered "cognitively impaired" if they show at least a $15 \%$ decrease in cognitive task performance (Schneider and Kovelowski 1990; Schneider and Roeltgen 1993; Decamp and Schneider 2004, 2006; Decamp et al. 2004). Measurement of cognitive performance is by a computer-controlled touch-screen battery of tests that have been validated in this model. The so-called "chronic low-dose" MPTP-treated macaque monkeys develop impairments in the performance of spatial delayed responses, delayed matching-to-sample, delayed alternation, object retrieval and discrimination reversal tasks, as well as a variety of specific impairments of attentional and executive functions (Schneider and Kovelowski 1990; Schneider and Roeltgen 1993; Decamp and Schneider 2004, 2006; Decamp et al. 2004). This model has particular relevance to the evaluation and development of cognition-enhancing drugs to treat the neuropsychological aspects of $\mathrm{PD}$, in which frontostriatal dysfunction has been implicated.

\section{Sleep/Chronobiological Disturbances}

Sleep disturbances, excessive daytime sleepiness (EDS), and rapid eye movement (REM) sleep deregulation are among the most frequent and disabling nonmotor manifestations of Parkinson's disease (PD) (Arnulf et al. 2002; Ghorayeb et al. 2007). They may precede the cardinal motor features of the disease by years and may serve as early biomarkers of the premotor phase of PD. To replicate the sleep-wake disorders of $\mathrm{PD}$ and to understand the temporal relationship between these sleep disturbances and the occurrence of parkinsonism, Ghorayeb and collaborators performed long-term continuous electroencephalographic monitoring of vigilance states in unrestrained rhesus monkeys using an implanted miniaturized telemetry device and tested the effect of MPTP intoxication on their sleep-wake organization (Barraud et al. 2009). MPTP injection yielded a dramatic disruption of sleep-wake architecture with reduced sleep efficacy that persisted years after MPTP administration. Primary deregulation of REM sleep and increased daytime sleepiness occurring before the emergence of motor symptoms were a striking feature of the MPTP effect. This was concomitant with a breakdown of dopaminergic homeostasis (Barraud et al. 2009). In the 
long term, partial reemergence of REM sleep paralleled the partial adaptation to parkinsonism, the latter being known to result from compensatory mechanisms within the dopaminergic system. Altogether, these findings highlight the suitability of the MPTP macaque model of PD as a tool to model the sleep/wake disturbances of the human disease. Ultimately, this may help in deciphering the specific role of neurotransmitter depletion in the occurrence of these symptoms.

\section{Dyskinesia}

Besides PD-symptoms, PD patients experience side effects of their long-term L-dopa therapy. Such therapy is confounded by the development of adverse events related to fluctuations in motor response. Motor fluctuations include on-off fluctuations, sudden, unpredictable changes in mobility, and the wearing-off phenomenon, a decrease in the duration of action of L-dopa. However, the most debilitating class of motor fluctuation is involuntary movements known as L-dopa-induced dyskinesia (LID). Four species have been regularly used, namely the macaque monkeys (macaca mulatta and macaca fascicularis) (Bezard et al. 2003, 2004; Berton et al. 2009; Ahmed et al. 2010; Fasano et al. 2010; Rylander et al. 2010), the marmoset (callithrix jacchus) (Pearce et al. 1998; Henry et al. 2001, 2003; Smith et al. 2002; Savola et al. 2003; Hill et al. 2004a,b) and the squirrel (Saimiri sciureus) monkeys (Langston et al. 2000; Hsu et al. 2004), although the most human-like ones are displayed by the macaques (Bezard et al. 2001a; Jenner 2008). Those macaques with LID show various combinations of choreic-athetoid (i.e., characterized by constant writhing and jerking motions), dystonic and even ballistic movements (i.e., large-amplitude flinging, flailing movements), although less frequently for those latter (Bezard et al. 2003, 2004; Gold et al. 2007; Berton et al. 2009; Ahmed et al. 2010; Fasano et al. 2010; Rylander et al. 2010). Both the repertoire and severity of dyskinesia are not distinguishable from LID occurring in PD patients (e.g., Bezard et al. 2003; Ahmed et al. 2010; Fasano et al. 2010).

\section{Behavioral Assessment}

The various symptoms require to be precisely quantified for demonstrating for instance the efficacy of an experimental therapeutic. Most studies rely on UPDRS-like clinical assessments (Imbert et al. 2000; Bezard and Przedborski 2011). Those measurements must at least be performed in double-blind and must be performed watching posthoc video-recordings of animals behaving in vast environments allowing proper motor behavior to develop (Bezard et al. 2003, 2004; Gold et al. 2007; Berton et al. 2009; Ahmed et al. 2010; Fasano et al, 2010; Rylander et al. 2010). Not only the procedure ensures reproducibility and environment control but it allows further check by independent examiners or trained neurologists. Such simple and obvious criteria are unfortunately seldom fulfilled.

Clinical assessments must be accompanied by automated man-free measurement of locomotor activity such as infrared monitoring, video-based measurement of traveled distance (Bezard et al. 2003, 2004; Gold et al. 2007; Berton et al. 2009; Ahmed et al. 2010; Fasano et al. 2010; Rylander et al. 2010), mechanograhic analysis (Doudet et al. 1985, 1986; Benazzouz et al. 1993), or even better although still challenging, whole body kinematics analysis (Courtine et al. 2005a,b). To increase the translationality of the MPTP monkey model, animals could also be submitted to a variety of behavioral tasks that would assess both the motor and nonmotor functions. Such tasks range from a simple food-retrieval task (Bezard et al. 1997) up to a comprehensive neuropsychological assessment (i.e., CANTAB-like battery of tests) (Schneider and Kovelowski 1990; Schneider and Roeltgen 1993; Decamp and Schneider 2004, 2006) passing by object retrieval tasks with various cognitive loads (Schneider and Roeltgen 1993; Schneider et al. 1998).

\section{Roadblocks}

Altogether, these data show the amazing potential of the MPTP monkey model as a (almost perfect) phenocopy of PD. Such phenocopy is made possible because MPTP is all but specific to nigrostriatal DA neurons and is more obvious 
G. Porras et al.

in animals rendered parkinsonian with chronic regimen of intoxication.

Selecting the best species/regimen remains however a challenge. Four key criteria should be considered: (1) What stage of the disease do you want to study? (2) what symptoms (if any) is key to your experiment? (3) What anatomo-pathological features do you want to obtain? (4) How reproducible your model should be? Ideally a single model should be able to address all possible questions although we have seen that specific symptoms or feature could be expressed by a given species (i.e., the $\mathrm{PD}$ rest tremor is only displayed by the African green monkey).

As one might need to deal with different stages of the disease, i.e., the prodromal/presymptomatic, the symptomatic or the dyskinetic phases, a chronic slowly progressing model should be favored (Schneider 1990; Bezard et al. 1997, 2001c). PD is a bilateral multisystemic disease in nature and systemic exposure will lead to a variety of lesions as reviewed above. Although the daily management of animals is complicated by potential threat of animal's health status (adipsia, aphagia, loss of body weight), systemic exposure to the toxin is required (Schneider 1990; Bezard et al. 1997, 2001c). Trained staffs are required to follow the animal health status and body weight on a daily basis. Gavage should be introduced quite early in the intoxication process as a safety measure with proven efficacy in increasing the survival rate. In chronic regimen, intoxication should often be stopped before obtaining a full-blown syndrome as symptoms tend to worsen once they have clearly appeared. It is therefore recommended to rely on the expertise of trained team before starting any new experiment. The more chronic the regimen is, the better it is to introduce dopamine transporter imaging to follow on going neurodegenerative process and stop intoxication at the desired extent of denervation (Prunier et al. 2003). To rely on a model in which the kinetics of nigrostriatal denervation is know either with in vivo imaging (Prunier et al. 2003) or with postmortem endpoints (Bezard et al, 2001c; Meissner et al. 2003) is clearly an advantage. This is, however, seldom the case as a single model fulfills so far this requirement. In the same way, primate models of PD have often been criticized for their supposed lack of reproducibility. This is in fact the consequence of the heterogeneity in the primate population used by most investigators. Most labs access with difficulty to primates and use animals of both genders, of varying body range and age, and most likely from different genetic backgrounds (e.g., there are differences between cynomolgus macaques from Mauritius, China, and Philippines). In our laboratory we use exclusively F2-bred macaques. Using our classic intoxication paradigm replicating PD progression over a month in the female cynomolgus macaque (Bezard et al. 2001c; Meissner et al. 2003), symptom reach the clinical criterion for stopping MPTP at $15.6 \pm 1.01 \mathrm{~d}$. Such an amazing result derives from $n=298$ female cynomolgus of 3 years of age and $3.3 \pm 0.2 \mathrm{~kg}$. These numbers highlight the need for homogeneity of monkey population just like we do work with rodents otherwise.

\section{MPTP beyond Primates}

Although we here focus on MPTP primate models of PD, we do not ignore the value of other MPTP models (see Tieu 2011). MPTP has been shown to be toxic in a large range of species (Bezard et al. 1998). The most popular species, besides primates, is the mouse (Heikkila et al. 1984), as rats were found to be resistant to this toxin (Chiueh et al. 1984). MPTP models as a whole fall into two categories, the so-called pathogenic and symptomatic/pathophysiologic models (Bezard and Przedborski 2011).

The pathogenic models include the MPTP toxin models (as well as the non-PD-related genetic mutations such as the MitoPark mice (Ekstrand et al. 2007). The value of the pathogenic models rests on the premise that dopaminergic neurons die by a stereotyped cascade that can be activated by a range of insults, including toxins whose relevance to PD per se remain uncertain. In that respect, the MPTP mouse models should be favored for obvious practical, economical and ethical reasons. Although the authors consider that the MPTP mouse models are pivotal in our past and current progress toward the 
understanding of PD neurodegeneration, we should still consider primates at some stage as primate dopaminergic neurons are different in nature form mouse dopaminergic neurons. Best example is the lack of neuromelanin in rodents that is characteristic of the "nigra" in primate (and man).

The MPTP monkey models clearly represent most of the existing symptomatic/pathophysiologic models, which aim at recapitulating the motor manifestations of PD (whether or not they display signs of neurodegeneration), and are used to develop symptomatic therapies or to study circuit-related questions. Because we believe that only nonhuman primates accurately mimic the motor expression of $\mathrm{PD}$, in our opinion, these are the only animals that are optimal for such studies. MPTP mouse models for instance fail to replicate symptomatic manifestation of PD.

\section{CONCLUDING REMARKS}

The take-home message when defining the model of choice is as follows:

1. use an old world primate species (behavioral repertoire and primate-specific genes);

2. favor a chronic intoxication for progressiveness (and access to all key periods in disease evolution);

3. select a systemic route for inducing multisystemic lesions (full pathological picture);

4. study both motor and nonmotor symptoms (comprehensive behavioral impairment); and

5. demonstrate reproducibility (scientific comparisons).

Although utopian that a single model could reproduce $\mathrm{PD}$, the $\mathrm{MPTP} \operatorname{model}(\mathrm{s}) \operatorname{mimic}(\mathrm{s})$ most of it and remain the model of choice in translational research for $\mathrm{PD}$.

\section{ACKNOWLEDGMENTS}

This work was supported by ANR-07-MNP TRAFINLID and ANR-08-MNP-018 MCHPRIMAPARK Agence Nationale de la Recherche grants (EB), Federation pour la Recherche sur le Cerveau grant (EB), Biothèque Primate Centre National de la Recherche Scientifique Life Sciences Department (EB), Conseil Régional d'Aquitaine (EB). The Universite Bordeaux Segalen and the Centre National de la Recherche Scientifique provided the infrastructural support.

\section{REFERENCES}

${ }^{*}$ Reference is also in this collection.

Ahmed MR, Berthet A, Bychkov E, Porras G, Li Q, Bioulac BH, Carl YT, Bloch B, Kook S, Aubert I, et al. 2010. Lentiviral overexpression of GRK6 alleviates L-dopa-induced dyskinesia in experimental Parkinson's disease. Sci Transl Med 2: 28ra28.

Arnulf I, Konofal E, Merino-Andreu M, Houeto JL, Mesnage V, Welter ML, Lacomblez L, Golmard JL, Derenne JP, Agid Y. 2002. Parkinson's disease and sleepiness: An integral part of PD. Neurology 58: 1019-1024.

Barraud Q, Lambrecq V, Forni C, McGuire S, Hill M, Bioulac B, Balzamo E, Bezard E, Tison F, Ghorayeb I. 2009. Sleep disorders in Parkinson's disease: The contribution of the MPTP non-human primate model. Exp Neurol 219: 574-582.

Barraud Q, Obeid I, Aubert I, Barriere G, Contamin H, McGuire S, Ravenscroft P, Porras G, Tison F, Bezard E, et al. 2010. Neuroanatomical study of the all diencephalospinal pathway in the non-human primate. PLoS One 5: e13306.

Belanger N, Gregoire L, Hadj Tahar A, Bedard PJ. 2003. Chronic treatment with small doses of cabergoline prevents dopa-induced dyskinesias in parkinsonian monkeys. Mov Disord 18: 1436-1441.

Benazzouz A, Gross C, Bioulac B. 1992. MPTP-induced hemiparkinsonism in monkeys: Behavioral, mechanographic, electromyographic and immunohistochemical studies. Exp Brain Res 90: 116-120.

Benazzouz A, Gross C, Feger J, Boraud T, Bioulac B. 1993. Reversal of rigidity and improvement in motor performance by subthalamic high frequency stimulation in MPTP-treated monkeys. Eur J Neurosci 5: 382-389.

Berton O, Guigoni C, Li Q, Bioulac BH, Aubert I, Gross CE, Dileone RJ, Nestler EJ, Bezard E. 2009. Striatal overexpression of DeltaJunD resets L-DOPA-induced dyskinesia in a primate model of Parkinson disease. Biol Psychiatry 66: 554-561.

Bezard E, Imbert C, Deloire X, Bioulac B, Gross C. 1997. A chronic MPTP model reproducing the slow evolution of Parkinson's disease: Evolution of motor symptoms in the monkey. Brain Res 766: 107-112.

Bezard E, Imbert C, Gross CE. 1998. Experimental models of Parkinson's disease: From the static to the dynamic. Rev Neurosci 9: 71-90.

Bezard E, Brotchie JM, Gross CE. 2001a. Pathophysiology of levodopa-induced dyskinesia: Potential for new therapies. Nature Rev Neurosci 2: 577-588. 
G. Porras et al.

Bezard E, Crossman AR, Gross CE, Brotchie JM. 2001b. Structures outside the basal ganglia may compensate for dopamine loss in the pre-symptomatic stages of Parkinson's disease. FASEB J 15: 1092-1094.

Bezard E, Dovero S, Prunier C, Ravenscroft P, Chalon S, Guilloteau D, Bioulac B, Brotchie JM, Gross CE. 2001c. Relationship between the appearance of symptoms and the level of nigrostriatal degeneration in a progressive MPTP-lesioned macaque model of Parkinson's disease. J Neurosci 21: 6853-6861.

Bezard E, Ferry S, Mach U, Stark H, Leriche L, Boraud T, Gross CE, Sokoloff P. 2003. Attenuation of levodopa-induced dyskinesia by normalizing dopamine D3 receptor function. Nature Med 9: 762-767.

Bezard E, Hill MP, McGuire SG, Crossman AR, Brotchie JM, Michel A, Grimée R., Klitgaard H. 2004. Levetiracetam improves choreic levodopa-induced dyskinesia in the MPTP-treated macaque. Eur J Pharmacol 485: 159-164.

Bezard E, Przedborski S. 2011. A tale on animal models of Parkinson's Disease. Mov Disord 26: 993-1002.

Chaumette T, Lebouvier T, Aubert P, Lardeux B, Qin C, Li Q, Accary D, Bézard E, Varannes SBd, Derkinderen P, et al. 2009. Neurochemical plasticity in the enteric nervous system of a primate animal model of experimental Parkinsonism. Neurogastroenterol Motil 21: 215-222.

Chiueh CC, Markey SD, Burns RS, Johannessen JN, Jacobowitz DM, Kopin IJ. 1984. Neurochemical and behavioral effects of MPTP in rat, guinea pig and monkey. Psychopharmacol Bull 20: 548-553.

Courtine G, Roy RR, Hodgson J, McKay H, Raven J, Zhong H, Yang H, Tuszynski MH, Edgerton VR. 2005a. Kinematic and EMG determinants in quadrupedal locomotion of a non-human primate (Rhesus). J Neurophysiol 93: 3127-3145.

Courtine G, Roy RR, Raven J, Hodgson J, McKay H, Yang H, Zhong H, Tuszynski MH, Edgerton VR. 2005b. Performance of locomotion and foot grasping following a unilateral thoracic corticospinal tract lesion in monkeys (Macaca mulatta). brain 128: 2338-2358.

Crossman AR, Mitchell IJ, Sambrook MA. 1985. Regiona brain uptake of 2-deoxyglucose in N-methyl-4-phenyl1,2,3,6-tetrahydropyridine (MPTP)-induced parkinsonism in the macaque monkey. Neuropharmacology 24: 587-591.

Decamp E, Schneider JS. 2004. Attention and executive function deficits in chronic low-dose MPTP-treated nonhuman primates. Eur J Neurosci 20: 1371-1378.

Decamp E, Schneider JS. 2006. Effects of nicotinic therapies on attention and executive functions in chronic lowdose MPTP-treated monkeys. Eur J Neurosci 24: 2098 2104 .

Decamp E, Tinker JP, Schneider JS. 2004. Attentional cueing reverses deficits in spatial working memory task performance in chronic low dose MPTP-treated monkeys. Behav Brain Res 152: 259-262.

Di Monte DA, McCormack A, Petzinger G, Janson AM, Quik M, Langston WJ. 2000. Relationship among nigrostriatal denervation, parkinsonism, and dyskinesias in the MPTP primate model. Mov Disord 15: 459-466.

Doudet D, Gross C, Lebrun-Grandie P, Bioulac B. 1985 MPTP primate model of Parkinson's disease: A mecha- nographic and electromyographic study. Brain Res 335: 194-199.

Doudet D, Gross C, Lebrun-Grandié P, Bioulac B. 1986. Mechanographic and kinematic studies of a voluntary elbow movement in MPTP-treated monkeys. Effects of L-Dopa therapies. In MPTP: A neurotoxin producing a parkinsonian syndrome (ed. Sanford P, Markey P), pp. 651-666. Academic Press, Orlando, FL.

Doudet DJ, Gross C, Arluison M, Bioulac B. 1990. Modifications of precentral cortex discharges and EMG activity in monkey with MPTP-induced lesions of DA nigral neurons. Exp Brain Res 80: 177-188.

Ekstrand MI, Terzioglu M, Galter D, Zhu S, Hofstetter C, Lindqvist E, Thams S, Bergstrand A, Hansson FS, Trifunovic A, et al. 2007. Progressive parkinsonism in mice with respiratory-chain-deficient dopamine neurons. Proc Natl Acad Sci 104: 1325-1330.

Fasano S, Bezard E, D’Antoni A, Francardo V, Indrigo M, Qin L, Dovero S, Cerovic M, Cenci MA, Brambilla R. 2010. Inhibition of Ras-guanine nucleotide-releasing factor 1 (Ras-GRF1) signaling in the striatum reverts motor symptoms associated with L-dopa-induced dyskinesia. Proc Natl Acad Sci 107: 21824-21829.

Fernagut PO, Li Q, Dovero S, Chan P, Wu T, Ravenscroft P, Hill M, Chen Z, Bezard E. 2010. Dopamine transporter binding is unaffected by L-DOPA administration in normal and MPTP-treated monkeys. Plos One 5: e14053.

Ghorayeb I, Loundou A, Auquier P, Dauvilliers Y, Bioulac B, Tison F. 2007. A nationwide survey of excessive daytime sleepiness in Parkinson's disease in France. Mov Disord 22: $1567-1572$.

Gold SJ, Hoang CV, Potts BW, Porras G, Pioli E, Kim KW, Nadjar A, Qin C, LaHoste GJ, Li Q, et al. 2007. RGS9-2 negatively modulates L-3,4-dihydroxyphenylalanine-induced dyskinesia in experimental Parkinson's disease. $J$ Neurosci 27: 14338-14348.

Guehl D, Pessiglione M, Francois C, Yelnik J, Hirsch EC, Feger J, Tremblay L. 2003. Tremor-related activity of neurons in the 'motor' thalamus: Changes in firing rate and pattern in the MPTP vervet model of parkinsonism. Eur J Neurosci 17: 2388-2400.

Guigoni C, Dovero S, Aubert I, Qin L, Bioulac BH, Bloch B, Gurevich EV, Gross CE, Bezard E. 2005. Levodopainduced dyskinesia in MPTP-treated macaque is not dependent of the extent and pattern of the nigrostrial lesion. Eur J Neurosci 22: 283-287.

Hadj Tahar A, Gregoire L, Darre A, Belanger N, Meltzer L, Bedard PJ. 2004. Effect of a selective glutamate antagonist on L-dopa-induced dyskinesias in drug-naive parkinsonian monkeys. Neurobiol Dis 15: 171-176.

Heikkila RE, Hess A, Duvoisin RC. 1984. Dopaminergic neurotoxicity of MPTP in mice. Science 224: 1451-1453.

Henry B, Fox SH, Crossman AR, Brotchie JM. 2001. muand $\delta$-Opioid receptor antagonists reduce levodopa-induced dyskinesia in the MPTP-lesioned primate model of Parkinson's Disease. Exp Neurol 171: 139-146.

Henry B, Duty S, Fox SH, Crossman AR, Brotchie JM. 2003. Increased striatal pre-proenkephalin B expression is associated with dyskinesia in Parkinson's disease. Exp Neurol 183: $458-468$.

Hill MP, Brotchie JM, McGuire S, Crossman AR, Bezard E, Grimée R, Klitgaard H. 2004a. Levetiracetam interferes 
with L-dopa priming process in the MPTP-lesioned drug naïve marmoset. Clin Neuropharmacol 27: 171-177.

Hill MP, Ravenscroft P, Bezard E, Crossman AR, Brotchie JM, Michel A, Grimee R, Klitgaard H. 2004b. Levetiracetam potentiates the antidyskinetic action of amantadine in the 1-Methyl-4-phenyl-1,2,3,6-tetrahydropyridine (MPTP)-lesioned primate model of Parkinson's Disease. J Pharmacol Exp Ther 310: 386-394.

Hsu A, Togasaki DM, Bezard E, Sokoloff P, Langston JW, Di Monte DA, Quik M. 2004. Effect of the D3 dopamine receptor partial agonist BP897 [N-[4-(4-(2-methoxyphenyl)piperazinyl)butyl]-2-naphthamide] on L-3,4-dihydroxyphenylalanine-induced dyskinesias and parkinsonism in squirrel monkeys. J Pharmacol Exp Ther 311: 770-777.

Imbert C, Bezard E, Guitraud S, Boraud T, Gross CE. 2000. Comparison between eight clinical rating scales used for the assessment of MPTP-induced parkinsonism in the macaque monkey. J Neurosci Meth 96: 71-76.

Iravani MM, Jackson MJ, Kuoppamaki M, Smith LA, Jenner P. 2003. 3,4-methylenedioxymethamphetamine (ecstasy) inhibits dyskinesia expression and normalizes motor activity in 1-methyl-4-phenyl-1,2,3,6-tetrahydropyridinetreated primates. J Neurosci 23: 9107-9115.

Iravani MM, Syed E, Jackson MJ, Johnston LC, Smith LA, Jenner P. 2005. A modified MPTP treatment regime produces reproducible partial nigrostriatal lesions in common marmosets. Eur J Neurosci 21: 841-854.

Jan C, Pessiglione M, Tremblay L, Tandé D, Hirsch EC, François C. 2003. Quantitative analysis of dopaminergic loss in relation to functional territories in MPTP-treated monkeys. Eur J Neurosci 18: 2082-2086.

Jenner P. 2008. Molecular mechanisms of L-DOPA-induced dyskinesia. Nat Rev Neurosci 9: 665-677.

Kordower JH, Liu Y-T, Winn SR, Emerich DF. 1995. Encapsulated PC12 cell transplants into hemiparkinsonian monkeys: A behavioral, neuroanatomical and neurochemical analysis. Cell Trans 4: 55-171.

Langston JW, Forno LS, Rebert CS, Irwin I. 1984. Selective nigral toxicity after systemic administration of 1 methyl-4-phenyl 1-1,2,3,6, tetrahydropyridine (MPTP) in the squirrel monkey. Brain Res 292: 390-394.

Langston JW, Quik M, Petzinger G, Jakowec M, Di Monte DA. 2000. Investigating levodopa-induced dyskinesias in the Parkinsonian primate. Ann Neurol 47: S79-S89.

Meissner W, Prunier C, Guilloteau D, Chalon S, Gross CE, Bezard E. 2003. Time course of nigrostriatal degeneration in a progressive MPTP-lesioned macaque model of Parkinson's disease. Mol Neurobiol 28: 87-96.

Moratalla R, Quinn B, DeLanney LE, Irwin I, Langston JW, Graybiel AM. 1992. Differential vulnerability of primate caudate-putamen and striosome- matrix dopamine systems to the neurotoxic effects of 1-methyl-4-phenyl- 1,2,3,6-tetrahydropyridine. Proc Natl Acad Sci 89: 3859-3863.

Morissette M, Grondin R, Goulet M, Bedard PJ, Di Paolo T. 1999. Differential regulation of striatal preproenkephalin and preprotachykinin mRNA levels in MPTP-lesioned monkeys chronically treated with dopamine D-1 or D-2 receptor agonists. J Neurochem 72: 682-692.

Ouattara B, Belkhir S, Morissette M, Dridi M, Samadi P, Gregoire L, Meltzer LT, Di Paolo T. 2009. Implication of NMDA receptors in the antidyskinetic activity of caber-
MPTP Primate Models of Parkinson's Disease

goline, CI-1041, and Ro 61-8048 in MPTP monkeys with levodopa-induced dyskinesias. J Mol Neurosci 38: $128-142$.

Pearce RK, Banerji T, Jenner P, Marsden CD. 1998. De novo administration of ropinirole and bromocriptine induces less dyskinesia than L-dopa in the MPTP-treated marmoset. Mov Disord 13: 234-241.

Pifl C, Schingnitz G, Hornykiewicz O. 1991. Effect of 1methyl-4-phenyl-1,2,3,6-tetrahydropyridine on the regional distribution of brain monoamines in the rhesus monkey. Neuroscience 44: 591-605.

Prunier C, Bezard E, Mantzarides M, Besnard JC, Baulieu JL, Gross CE, Guilloteau D, Chalon S. 2003. Presymptomatic diagnosis of experimental parkinsonism with 123I-PE2I SPECT. Neuroimage 19: 810-816.

Purisai MG, McCormack AL, Langston WJ, Johnston LC, Di Monte DA. 2005. $\alpha$-synuclein expression in the substantia nigra of MPTP-lesioned non-human primates. Neurobiol Dis 20: 898-906.

Raz A, Vaadia E, Bergman H. 2000. Firing patterns and correlations of spontaneous discharge of pallidal neurons in the normal and the tremulous 1-methyl-4-phenyl1,2,3,6-tetrahydropyridine vervet model of parkinsonism. J Neurosci 20: 8559-8571.

Roeltgen DP, Schneider JS. 1991. Chronic low-dose MPTP in nonhuman primates: a possible model for attention deficit disorder. J Child Neurol 6 (Suppl): S82-S89.

Roeltgen DP, Schneider JS. 1994. Task persistence and learning ability in normal and chronic low dose MPTP-treated monkeys. Behav Brain Res 60: 115-124.

Rose S, Nomoto M, Jackson EA, Gibb WRG, Jaehnig P, Jenner P, Marsden CD. 1993. Age-related effects of MPTP treatment of common marmosets. Eur J Pharmacol 230: 177-185.

Rylander D, Iderberg H, Li Q, Dekundy A, Zhang J, Li H, Baishen R, Danysz W, Bezard E, Cenci MA. 2010. A mGluR5 antagonist under clinical development improves L-DOPA-induced dyskinesia in parkinsonian rats and monkeys. Neurobiol Dis 39: 352-361.

Savola JM, Hill M, Engstrom M, Merivuori H, Wurster S, McGuire SG, Fox SH, Crossman AR, Brotchie JM. 2003. Fipamezole (JP-1730) is a potent $\alpha 2$ adrenergic receptor antagonist that reduces levodopa-induced dyskinesia in the MPTP-lesioned primate model of Parkinson's disease. Mov Disord 18: 872-883.

Schneider JS. 1990. Chronic exposure to low doses of MPTP. II. Neurochemical and pathological consequences in cognitively-impaired, motor asymptomatic monkeys. Brain Res 534: 25-36.

Schneider JS, Kovelowski CJ. 1990. Chronic exposure to low doses of MPTP. I. Cognitive deficits in motor asymptomatic monkeys. Brain Res 519: 122-128.

Schneider JS, Roeltgen DP. 1993. Delayed matching-to-sample, object retrieval, and discrimination reversal deficits in chronic low dose MPTP-treated monkeys. Brain Res 615: $351-354$.

Schneider JS, McLaughlin WW, Roeltgen DP. 1992. Motor and non-motor behavioral deficits in monkeys made hemiparkinsonian by intracarotid MPTP infusion. $\mathrm{Neu}$ rology 42: 1565-1572. 


\section{G. Porras et al.}

Schneider JS, Van Velson M, Menzaghi F, Lloyd GK. 1998 Effects of the nicotinic acetylcholine receptor agonist SIB-1508Y on object retrieval performance in MPTPtreated monkeys: comparison with levodopa treatment. Ann Neurol 43: 311-317.

Smith LA, Tel BC, Jackson MJ, Hansard MJ, Braceras R, Bonhomme C, Chezaubernard C, Del Signore S, Rose S, Jenner P. 2002. Repeated administration of piribedil induces less dyskinesia than L- dopa in MPTP-treated com- mon marmosets: A behavioural and biochemical investigation. Mov Disord 17: 887-901.

* Tieu K. 2011. A guide to neurotoxic animal models in Parkinson's disease. Cold Spring Harb Perspect Med doi: 10.1101/cshperspect.a009316.

Vital A, Li Q, Canron MH, Ravenscroft P, Hill M, Bezard E. 2010. Comprehensive pathological analysis in MPTPtreated macaques reveal widespread synucleopathy and tauopathy. Mov Disord 25: S203-S203. 


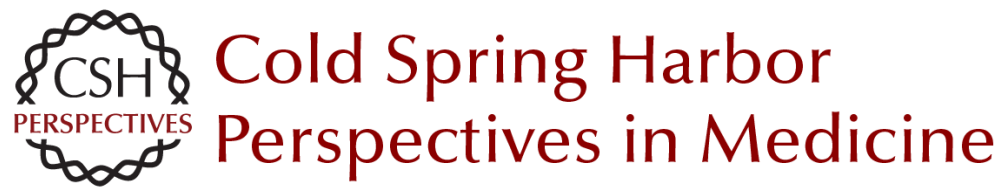

\section{Modeling Parkinson's Disease in Primates: The MPTP Model}

Gregory Porras, Qin Li and Erwan Bezard

Cold Spring Harb Perspect Med 2012; doi: 10.1101/cshperspect.a009308 originally published online December 22, 2011

\section{Subject Collection Parkinson's Disease}

Functional Neuroanatomy of the Basal Ganglia José L. Lanciego, Natasha Luquin and José A. Obeso

Animal Models of Parkinson's Disease: Vertebrate Genetics Yunjong Lee, Valina L. Dawson and Ted M. Dawson

Innate Inflammation in Parkinson's Disease V. Hugh Perry

Parkinson's Disease and Parkinsonism:

Neuropathology Dennis W. Dickson

Physiological Phenotype and Vulnerability in Parkinson's Disease

D. James Surmeier, Jaime N. Guzman, Javier Sanchez, et al.

Clinical Approach to Parkinson's Disease:

Features, Diagnosis, and Principles of Management João Massano and Kailash P. Bhatia

The Role of Autophagy in Parkinson's Disease Melinda A. Lynch-Day, Kai Mao, Ke Wang, et al.

Disruption of Protein Quality Control in Parkinson's Disease Casey Cook, Caroline Stetler and Leonard Petrucelli
Drosophila as a Model to Study Mitochondrial Dysfunction in Parkinson's Disease Ming Guo

Parkinsonism Due to Mutations in PINK1, Parkin, and DJ-1 and Oxidative Stress and Mitochondrial Pathways Mark R. Cookson

Programmed Cell Death in Parkinson's Disease Katerina Venderova and David S. Park

Genomics and Bioinformatics of Parkinson's

Disease Sonja W. Scholz, Tim Mhyre, Habtom Ressom, et al.

Motor Control Abnormalities in Parkinson's

Disease Pietro Mazzoni, Britne Shabbott and Juan Camilo Cortés

Parkinson's Disease: Gene Therapies Philippe G. Coune, Bernard L. Schneider and Patrick Aebischer

Functional Neuroimaging in Parkinson's Disease Martin Niethammer, Andrew Feigin and David Eidelberg

Leucine-Rich Repeat Kinase 2 for Beginners: Six Key Questions Lauren R. Kett and William T. Dauer

For additional articles in this collection, see http://perspectivesinmedicine.cshlp.org/cgi/collection/ 